\title{
Dissipation of six fungicides in greenhouse-grown tomatoes with processing and health risk
}

\author{
Magdalena Jankowska $^{1} \cdot$ Piotr Kaczynski $^{1} \cdot$ Izabela Hrynko $^{1} \cdot$ Bozena Lozowicka $^{1}$
}

Received: 3 October 2015 / Accepted: 7 February 2016/Published online: 9 March 2016

(C) The Author(s) 2016. This article is published with open access at Springerlink.com

\begin{abstract}
Greenhouse studies were conducted to evaluate the dissipation rate kinetics and estimate the behavior of selected pesticides after washing, peeling, simmering, and canning of tomato expressed as processing factor (PF). Two varieties (Marissa and Harzfeuer) were treated by six fungicides: azoxystrobin, boscalid, chlorothalonil, cyprodinil, fludioxonil, and pyraclostrobin at single and double dose and risk assessment defined as hazard quotient was performed. The QuEChERS method was used for sample preparation followed by liquid chromatography coupled with tandem mass spectrometry (LC-MS/MS). The dissipation of fungicides approximately fitted to a first-order kinetic model, with half-life values ranging from 2.49 and 2.67 days (cyprodinil) to 5.00 and 5.32 days (chlorothalonil) for Marissa and Harzfeuer variety, respectively. Results from processing studies showed that treatments have significant effects on the removal of the studied fungicides for both varieties. The PFs were generally less than 1 (between 0.01 and 0.90 ) and did not depend on variety. The dietary exposure assessed based on initial deposits of application at single and double dose on tomatoes and concentration after each process with PF correction showed no concern to consumer health. Our
\end{abstract}

Responsible editor: Laura McConnell

Electronic supplementary material The online version of this article (doi:10.1007/s11356-016-6260-x) contains supplementary material, which is available to authorized users.

Magdalena Jankowska

M.Jankowska@iorpib.poznan.pl

1 Laboratory of Pesticide Residues, Plant Protection Institute - National Research Institute, Chelmonskiego 22, 15-195 Bialystok, Poland results would be a useful tool for monitoring of fungicides in tomatoes and provide more understanding of residue behavior and risk posed by these fungicides.

Keywords Pesticides in tomatoes · Processed tomato pesticides $\cdot$ Fungicides in tomatoes $\cdot$ Dissipation of fungicides $\cdot$ Fungicide dissipation in tomatoes

\section{Introduction}

Tomatoes (Lycopersicon esculentum Mill.) belong to widely grown fruiting vegetables, and they are currently available for various purposes. The list of tomato cultivars includes about 25,000 varieties (Hixson 2015), and they are diversified in terms of skin color, size, shape, leaf type, and disease resistance code. This crop is susceptible to a number of diseases, thus fungicides have been widely used to control fungal pathogens in greenhouse systems. Some tomato varieties (Better Boy, Celebrity, Granadero, Red Chief, Marissa, Erophily, Matias, Swanson, Isabel, Kiveli, Sesenta, Genaros, Jury) are disease resistant, signifying that the plant is immune to a certain disease such as Alternaria stem canker, Fusarium wilt, Fusarium races 1,2, and 3; Nematodes, Tobacco mosaic virus, Stemphylium gray leaf spot, Verticillium wilt.

Fungicides from different groups have been widely used pre- and post-harvest to control fungal tomato pathogens (Matyjaszczyk 2015). Among them, members of the anilinopyrimidine, benzimidazole, carboxamide, chloronitrile, strobilurin, and tiazole family provide good control of tomato diseases. They have different modes of action such as systemic (absorbed through the leaves, stems, or roots) or contact (stay on the surfaces of plants), and they move in various ways after they come in contact with the plant. 
To control pesticide residues in vegetables, sensitive and reliable confirmatory methods are necessary (Han et al. 2013) to determine trace amounts these compounds. GC-MS/MS and LC-MS/MS have become valuable techniques in multiresidue analysis. They are currently the most efficient confirmatory tool for discriminating residues at ultra-trace levels (Ucles et al. 2014; Pico et al. 2007).

Pesticide residue monitoring study carried in tomatoes in European Union show that the most frequently detected groups are fungicides over the last years. Mainly dithiocarbamates, boscalid, pyraclostrobin, cyprodinil, fludioxonil, pyrimethanil, and chlorothalonil (EFSA Journal 2015) are detected which have been reported to be capable of causing endocrine disruption and embryotoxic, carcinogenic, and teratogenic effects (PPDB Pesticide Properties Database). The EU set tolerances (maximum residue limits, MRLs) for chlorothalonil, boscalid, cyprodinil, and pyraclostrobin in tomatoes: $6,3,1$, and $0.3 \mathrm{mg} / \mathrm{kg}$, respectively (EU Pesticide MRLs Database 2013). In contrast, the MRLs are very restrictive for baby food, and they are set at the level of $0.01 \mathrm{mg} / \mathrm{kg}$. However, there are no MRLs for the related processed commodities, such as tomato paste or juice. This gap may be attributed to the lack of processing study data of tomatoes. Therefore, it is necessary to obtain the residues of these pesticides during washing, peeling, juicing, simmering, and sterilization. The fate of a given pesticide needs to be also evaluated to determine dissipation kinetics of fungicides in order to adequately characterize the behavior of a pesticide and health risk assessment.

One way to remove pesticide residues from vegetables is their processing. Many researchers have studied the occurrence of pesticide residues in raw tomatoes (Lozowicka et al. 2015; Salghi et al. 2012), but few studies have focused on their behavior caused by canning. For the most part, pesticide residues in vegetables are reduced or concentrated after several processing such as washing, peeling, blanching, cooking, and sterilization (Holland et al. 1994; Kaushik et al. 2009; Timme and Walz-Tylla 2004). Many studies have been performed to determine how much residue can be eliminated by these types of processes (Berrada et al. 2010; Boulaid et al. 2005; Burchat et al. 1998; Rasmusssen et al. 2003; Lee and Jung 2009; Lentza-Rizos and Balokas 2001; Sakaliene et al. 2009). The effect of processing practices on residues is related with both commodity type and pesticide type (Burchat et al. 1998). However, concentration level after processing can sometimes result in a higher residue in food, for example, as a result of water loss (Timme and Walz-Tylla 2004).

Tomatoes are widely consumed all over the world (Certel et al. 2011) because they are one of the richest sources of lycopene, the potent age-defying antioxidant. After passing through various culinary and processing treatments, they are referred as a "functional food" that people should eat more often. Processed tomato fruits such as tomato juice, paste, soup, sauce, and ketchup are an important part of diet for many consumers because they contain the highest concentrations of bioavailable lycopene than fresh tomatoes. Tomato products are also widely used in children's feeding between the ages of one and three. The highest consumption of tomatoes indicates Italian population, especially toddlers (GEMS/ FOOD 2012).

Because of the negative effects of pesticides on human health for consumers, their intakes in tomatoes and its products are necessary to know. Thus, it is essential to evaluate the level of exposure from pesticide residue in food at the point of consumption after different processing (Bonnechere et al. 2012). Additionally, processing factor (PF: the ratio between residues' concentration in the processed commodity and that in the raw commodity) is the main parameter used in the dietary intake assessment of pesticides in processed agriculture commodities (Ling et al. 2011). Risk assessments (Lozowicka 2015; Łozowicka et al. 2009) and residue experiments for fungicides in tomatoes are required.

The aims of this study were to (1) evaluate dissipation kinetics of selected fungicides in field-treated two varieties of tomatoes conducted in an experimental greenhouse, to (2) investigate changes of selected pesticide residues after several processing methods in both varieties and provide information regarding the processing factor, and to (3) assess the health risk of consumers eating tomatoes with fungicide residues.

\section{Material and methods}

\section{Analytical standards and solvents}

The analytical standards of azoxystrobin, boscalid, chlorothalonil, cyprodinil, fludioxonil, and pyraclostrobin ( $<99.0 \%$ purity) were obtained from Dr. Ehrenstorfer (Augsburg, Germany). Stock solutions of six pesticides (around $1000 \mu \mathrm{g} / \mathrm{mL}$ ) were prepared separately by dissolving an accurately weighed amount of each reference standard in acetone. The combined working standard solutions were generated by serial dilution of the stock solutions with acetonitrile. The working standard solutions were used for the preparation of matrix-matched standards within the concentration range of $0.005-1.0 \mu \mathrm{g} / \mathrm{mL}$ and for the spiking of samples in the validation studies.

All reagents used pesticide residue grade and were obtained from J.T. Baker (Deventer, Holland).

\section{Choice of plants and fungicides}

Tomatoes were selected to this survey because they are highly consumed by adults as well as children, both in fresh and various processed forms. Among many varieties, two different varieties were chosen to compare 
dissipation behavior and pesticide concentration changes during processing. Variety Marissa is very resistant to many pathogens in cultivation in polish conditions while variety Harzfeuer is popular as a market tomato.

The investigations were carried out for six different active substances which were selected according to MRL exceeding, frequency, and level of detection in previous years (EFSA Journal 2015). Based on data of our laboratory, during government monitoring control of pesticide residues, positive detections were noted in $36 \%$ of tomato samples (56 samples) from the north-eastern region of Poland in 2010-2014. The most frequently detected pesticides were dithiocarbamates (19 samples) followed by chlorothalonil (16), fludioxonil (14), azoxystrobin (13), cyprodinil (11), and boscalid (9). Multiresidue samples (30) occurred most frequently in combination of azoxystrobin/chlorothalonil, cyprodinil/fludioxonil, chlorothalonil/dithiocarbamates, and boscalid/pyraclostrobin. Thus, according to those results, a list of potential harmful pesticides was established, and it contained the most often occurring fungicides: azoxystrobin, boscalid, chlorothalonil, cyprodinil, fludioxonil, and pyraclostrobin.

\section{Greenhouse trial}

The purpose of the greenhouse experiment was to produce two different tomato varieties (variety Marissa and Harzfeuer), exposed to the six selected fungicides.

\section{Variety characteristics}

Variety Marissa - variety description: early hybrid with indeterminate growth, cultivation in protected crops or open fields. The plant is vigorous, highly productive, produces uniform fruits of medium size, resistant to storage and transportation. Fruit weight: $150-170 \mathrm{~g}$, fruit color: dark red, number of seeds: 1000 seeds per one tomato. Variety Harzfeuer — variety description: German open pollinated variety. Round, slightly oblate beefsteak-type fruit, more acidic then sweet flavor and juicy. Regular leaf. Fruit weight: 70-90 g, fruit color: redorange, number of seeds: 250 seeds per one tomato.

\section{Cultivation of two varieties of tomatoes}

Tomato plants of both varieties were cultivated from May to September 2014 in the greenhouse $(6 \mathrm{~m} \times 4 \mathrm{~m})$ located in the Plant Protection Institute-National Research Institute in (Bialystok, Podlasie, Poland 53.139 ${ }^{\circ} \mathrm{N}, 23.159^{\circ} \mathrm{E}$ ) with no previous pesticide applications following recommended agronomic practices. The tomato plants were grown with a plant spacing $0.5 \mathrm{~m} \times 0.5 \mathrm{~m}$. There were three replications for each treatment (single for dissipation kinetics and double dose for processing treatments). The greenhouse plants were cultivated under controlled conditions with drip irrigation system.
Application of the fungicides

The experimental greenhouse plot was divided into six subplots with chemical application and one sub-plot for control without pesticide spraying. Treatments were carried out with fungicides: Amistar Opti 480 SC (containing active ingredients (a.i.): $80 \mathrm{~g}$ a.i./L azoxystrobin, $400 \mathrm{~g}$ a.i./L chlorothalonil; Syngenta), Signum 33 WG (267 g a.i./kg boscalid, $67 \mathrm{~g}$ a.i./kg pyraclostrobin; BASF), and Switch $62.5 \mathrm{WG}$ (375 g a.i./kg cyprodinil, $250 \mathrm{~g}$ a.i./kg fludioxonil; Syngenta) at fruiting stage (BBCH code: $81-89$, ripening of fruit and seed) (Fig. S1). Pesticides were sprayed individually on plants at single (for dissipation kinetics) and at double dose as recommended (for processing treatments) (Polish Ministry of Agriculture web site) by a specialized operator using knapsack sprayer to ensure sufficient pesticide primary deposit for the following processing. The plants were separated by foil. The temperature in the greenhouse ranged from 14 to $29^{\circ} \mathrm{C}$ and humidity ranged from 75 to $100 \%$ from the day of spraying until harvest.

\section{Sampling procedure}

Whole ripened tomato fruits of equal size after removing of stems (about $2 \mathrm{~kg}$ of tomatoes) were collected randomly from the control and treated plots of each treatment at $0(1 \mathrm{~h}), 1,2$, $3,5,8,11,14$, and 21 days after application of the fungicides at single dose for dissipation kinetics. Immediately after collecting, samples were packed in polyethylene bags and brought to the analytical laboratory, chopped and thoroughly mixed. The homogenized samples were stored deep frozen until analysis no longer than 1 month.

To investigate the effects of processing treatments on the reduction in residues, about $10 \mathrm{~kg}$ each variety of tomatoes were collected 3 days (the pre-harvest interval period of all PPP used according to their labels) after the spraying at double dose. The samples from each treatment were collected separately and were divided into three parts: the first part extracted and analyzed without any processing operation, the second subjected to the peeling process of raw tomatoes, and the third was processed step by step (washing $\rightarrow$ peeling $\rightarrow$ homogenization $\rightarrow$ simmering $\rightarrow$ canning) to obtain tomato paste (Fig. 1).

\section{Processing}

In general, the production procedures of canned tomato paste included five steps, i.e., washing, peeling, homogenization, simmering, and canning (Fig. 1). In the current study, samples (washed tomato, pulp, skin, puree, juice, seeds, paste, and canned tomato paste: Marissa sample (MS) MS2 $\div$ MS10 and Harzfeuer sample (HS) HS2 $\div$ HS10, from different processing steps were collected to determine and 
Fig. 1 Scheme of tomato processing

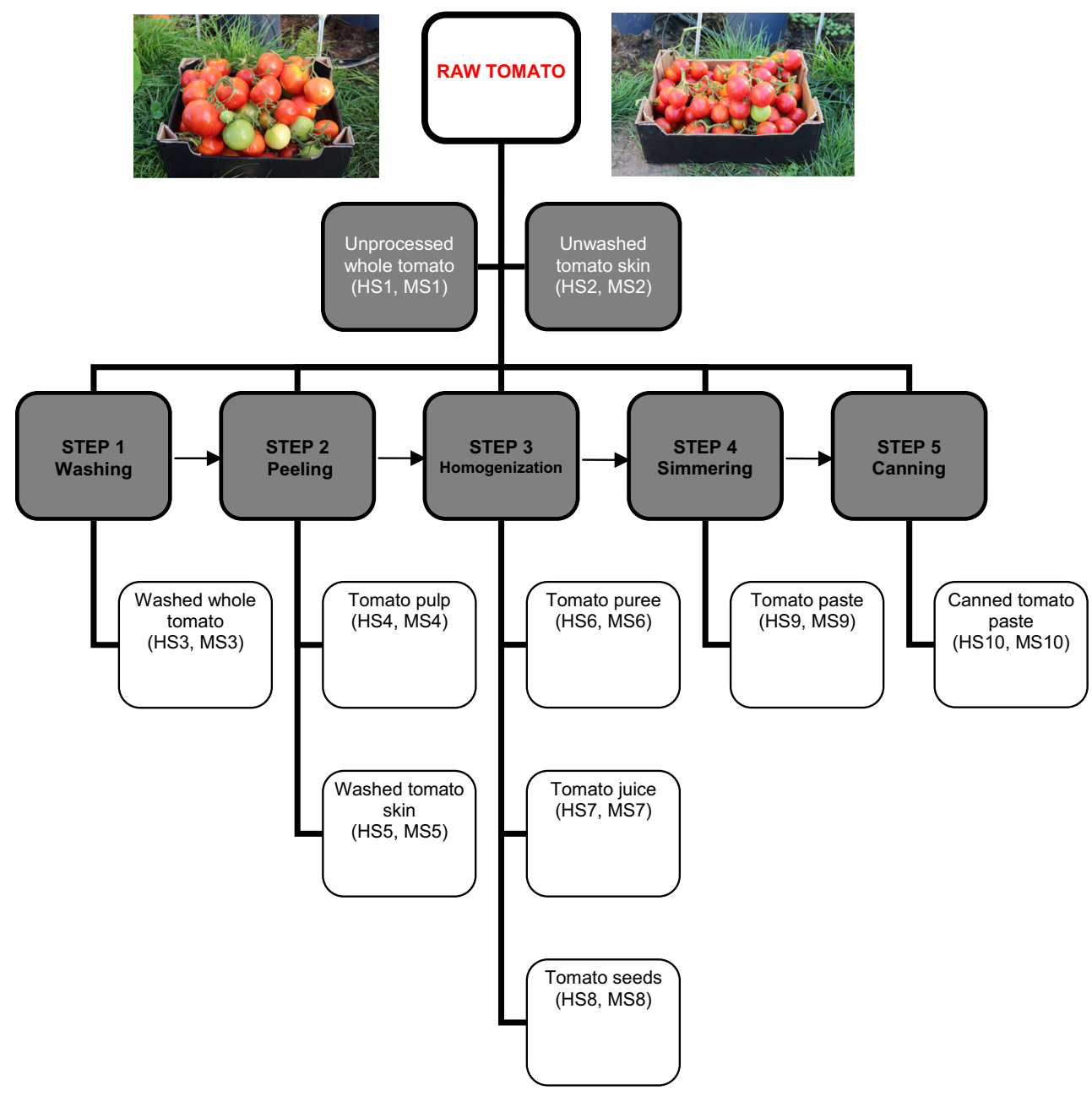

MS - sample variety Marissa

HS - sample variety Harzfeuer

S1-S10 samples taken to analysis investigate the variation of pesticide residues during the processing procedure. As shown in Fig. 1, part of tomatoes was divided from each variety which did not undergo any processing (MS1 and HS1).

The whole fruits of tomatoes were washed under running tap water for $1 \mathrm{~min}$ with rubbing with hands and the water was discarded (MS3, HS3). After washing, the whole fruits were peeled off with a knife to obtain tomato pulp (MS4, HS4) and washed tomato skin (MS5, HS5). Also, unwashed tomato skin was taken to analysis (MS2, HS2) before washing. Then, (1) part of the pulp was homogenized to obtain tomato puree (MS6, HS6) and (2) chopped into quarters; the seeds were (MS8, HS8) and excess juice was removed. The juice was homogenized using a blender (MS7, HS7). After that, the tomato pulp was simmered at a temperature of about $80{ }^{\circ} \mathrm{C}$ for $20 \mathrm{~min}$ (MS9, HS9) and then tomato paste was canned at $120^{\circ} \mathrm{C}$ for $20 \mathrm{~min}$ (MS10, HS10).

\section{Extraction and clean up}

The samples of tomato were processed and analyzed at the Laboratory of Pesticide Residues, Institute of Plant Protection-National Research Institute, Bialystok, Poland. All samples were extracted by a modified quick, easy, cheap, effective, rugged, and safe (QuEChERS) method according to EN 15662:2008 (European Standard 2008). The QuEChERS method was used for extraction and clean up of fungicide residues in fresh tomato samples and validated for processed tomato products. Representative $10 \mathrm{~g}$ of homogenized sample was weighed into a $50 \mathrm{~mL}$ PTFE centrifuge tube. Then, $10 \mathrm{~mL}$ of acetonitrile were added to the tube and the mixture was placed on a digital Vortex-Mixer (Velp Scientifica, Usmate, Italy) shaker for $5 \mathrm{~min}$ at $4500 \mathrm{rpm}$. Pre-packaged QuEChERS packet of sorbents and salts 
containing a total of $4 \mathrm{~g} \mathrm{MgSO}_{4}, 1 \mathrm{~g} \mathrm{NaCl}, 1 \mathrm{~g}$ trisodium citrate dehydrate, and $0.5 \mathrm{~g}$ disodium hydrogen citrate sesquihydrate was added, and the tube was immediately shaken for $1 \mathrm{~min}$ and then vortexed at full speed for 1 min. Then, the tube was centrifuged using a Rotina 420R centrifuge at $4500 \mathrm{rpm}$ (Hettich) for $10 \mathrm{~min}$ at $4500 \mathrm{rpm}$. The supernatant was transferred to a d-SPE tube containing $150 \mathrm{mg} \mathrm{MgSO}_{4}, 25 \mathrm{mg}$ PSA and then vortexed at full speed for $1 \mathrm{~min}$ and centrifuged briefly. Afterward, $1 \mathrm{~mL}$ of the upper layer was filtered through $0.2-\mathrm{mm}$ Nylon syringe filters $(15 \mathrm{~mm}$ diameter, Agela Technologies, China) into the appropriately labeled autosampler vial for LC-MS/MS analysis.

\section{Instrumentation and LC-MS/MS analytical conditions}

An Eksigent Ultra LC-100 (Eksigent Technologies, Dublin, CA, USA) liquid chromatography system was operated at a flow rate of $0.45 \mathrm{~mL} / \mathrm{min}$ without split chromatographic separation was carried out on a SunFire $\mathrm{C}_{18} 3.5 \mu \mathrm{m}, 2.1 \times 100 \mathrm{~mm}$ (Waters) analytical column, maintained at $50{ }^{\circ} \mathrm{C}$ during the experiments. The volume injected into the LC-MS/MS system was $10 \mu \mathrm{L}$. The binary mobile phase consisted of water with $0.5 \%$ formic acid and $5 \mathrm{mM}$ ammonium formate (phase A) and methanol with $0.5 \%$ formic acid and $5 \mathrm{mM}$ ammonium formate (phase B). The initial composition of $95 \% \mathrm{~A}$ and $5 \%$ $\mathrm{B}(v / v)$ was held for $2.0 \mathrm{~min}$., followed by linear ramping to $95 \%$ of B in $8 \mathrm{~min}$. and was held for $7 \mathrm{~min}$. After ramping, the mobile phase was returned to the initial composition in $2 \mathrm{~min}$. The total chromatographic run time was $25.0 \mathrm{~min}$. System MS/ MS 6500 QTRAP (AB Sciex Instruments, Foster City, CA) was used for mass spectrometric analysis, equipped with an electrospray ionization source (ESI) and atmospheric pressure chemical ionization (APCI). The capillary voltage was maintained at $5000 \mathrm{~V}$ for positive ion mode and in case of chlorothalonil at $-4500 \mathrm{~V}$ for negative ion mode, and the temperature of the turbo heaters was set at $450^{\circ} \mathrm{C}$. As the nebulizer gas (GS1), auxiliary gas (GS2), and curtain gas (CUR), the nitrogen was used at a pressure of 65,45 , and 35 psi, respectively. The nebulizer and collision gas was nitrogen. Optimization of the compounds was performed by injecting individual standard solutions directly into the source (flow injection analysis methods-FIA). Typical LC-MS/MS chromatogram of target fungicides presents Fig. 2.

\section{Method validation}

To analyze the selected pesticides, modified QuEChERS analytical method were used followed by liquid chromatography coupled with a mass spectrometer (LC-MS/MS).

Mean recovery test was performed using spiked blank tomato samples (raw, juice, and paste) at three different concentration levels of selected fungicides $(0.005,0.2$, and
$1.0 \mathrm{mg} / \mathrm{kg}$ ). The spiked samples were allowed to settle for $2 \mathrm{~h}$ at room temperature prior to the extraction step; this procedure was performed to distribute the pesticide evenly and ensure complete interaction with the sample matrix. The spiked samples were then processed according to the described procedure. The recoveries obtained from the extracted spiked samples were compared with those of the matrixmatched calibration solutions. Calibration curves of the matrix, which were prepared by using aforementioned method, automatically corrected the data for analytical recovery.

The mean recoveries of various concentrations of fungicides in raw tomato, tomato juice, and tomato paste were within 85.53-98.49, 87.53-92.01, and 86.17-96.12\%, respectively (Supplementary data, Table S3). These values were within the range expected for residue analysis. The reproducibility of recovery results, as indicated by relative standard deviations (RSDs) $<20 \%$, confirmed that the method is sufficiently reliable for pesticide analysis in this study (Document No. SANCO/12571/2013 2014).

The limits of quantification (LOQs) were defined as the minimum concentration of the analyte and quantified with acceptable accuracy and precision according to Document No. SANCO /12571/2013 (Document No. SANCO/12571/ 2013 2014). The limits of detection (LODs) for fungicides were calculated using signal-to-noise criteria $(\mathrm{S} / \mathrm{N}) ; \mathrm{LOD}=3$ (S/N). In this work, the LOQ was estimated to be $0.005 \mathrm{mg} / \mathrm{kg}$ and LOD was $0.002 \mathrm{mg} / \mathrm{kg}$ for all pesticides.

In addition of the in-house quality assurance programs, during 2006-2014, the laboratory successfully participated in nine inter-laboratory proficiency testing schemes in vegetable matrices organized and run by the Food Analysis Performance Assessment Scheme (FAPAS; Central Science Laboratory in York) and by the European Commission (in the beginning by the University of Uppsala and then by the University of Almeria) with satisfactory results (Supplementary data, Table S4).

\section{Dissipation kinetics}

The degradation kinetics of fungicides in two varieties of tomatoes were determined by plotting residue concentrations against time, and the maximum squares of correlation coefficients found were used to determine the equation of best-fit curves. For all samples, exponential relations were found to apply, corresponding to first-order rate equation. The persistence of fungicides is generally expressed in terms of half-life $\left(t_{1 / 2}\right)$ or DT50, i.e., time for the disappearance of pesticide to $50 \%$ of its initial concentration. The rate equation was calculated from the first-order equation: $C_{\mathrm{t}}=C_{0} \mathrm{e}^{-\mathrm{kt}}$, where $C_{\mathrm{t}}$ represents the concentration of the pesticide residues $(\mathrm{mg} / \mathrm{kg})$ at time (days), $C_{0}$ represents initial concentration $(\mathrm{mg} / \mathrm{kg})$, and $k$ is the first-order rate constant (per day) independent of $C_{\mathrm{t}}$ and $C_{0}$. The half-life $\left(t_{1 / 2}\right)$ was determined from the $k$ value for 


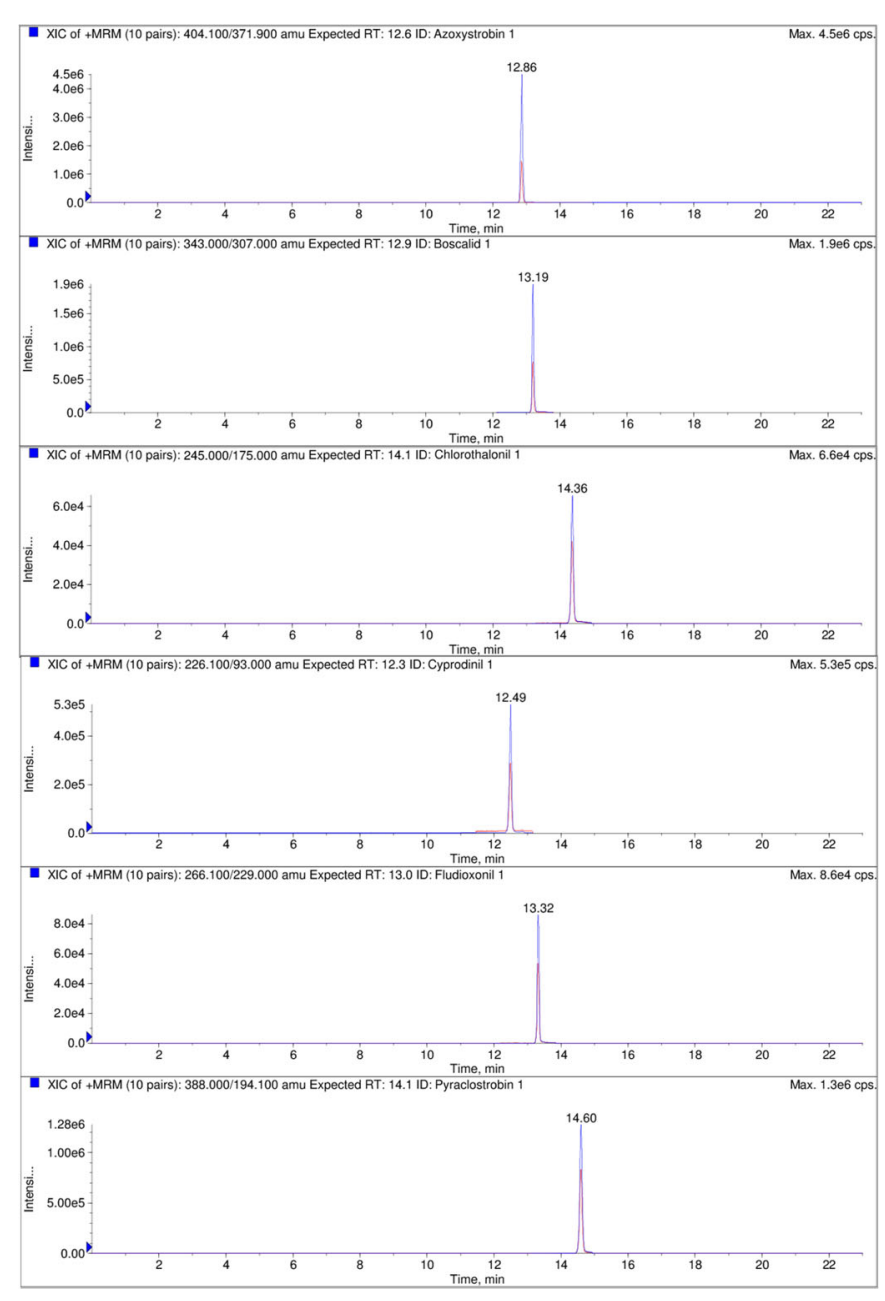

\begin{tabular}{|c|c|c|c|c|c|}
\hline Compound & $m / z$ & DP & EP & CE & CXP \\
\hline Azoxystrobin 1 & $404.1>371.9$ & 61 & 10 & 19 & 20 \\
\hline Azoxystrobin 2 & $404.1>344.0$ & 61 & 10 & 33 & 18 \\
\hline Boscalid 1 & $343.0>307.0$ & 116 & 10 & 27 & 16 \\
\hline Boscalid 2 & $343.0>140.0$ & 116 & 10 & 25 & 8 \\
\hline Chlorothalonil 1 & $245.0>175.0$ & -70 & -10 & -38 & -7 \\
\hline Chlorothalonil 2 & $245.0>182.0$ & -70 & -10 & -40 & -9 \\
\hline Cyprodinil 1 & $226.1>93.00$ & 71 & 10 & 43 & 12 \\
\hline Cyprodinil 2 & $226.1>77.0$ & 71 & 10 & 61 & 12 \\
\hline Fludioxonil 1 & $266.1>229.0$ & 65 & 10 & 17 & 12 \\
\hline Fludioxonil 2 & $266.1>157.9$ & 65 & 10 & 45 & 8 \\
\hline Pyraclostrobin 1 & $388.0>194.1$ & 41 & 10 & 17 & 12 \\
\hline Pyraclostrobin 2 & $388.0>163.1$ & 41 & 10 & 33 & 10 \\
\hline
\end{tabular}

Q - quadrupole, EP - entrance potential [V], DP - declustering potential [V], CE - collision energy [eV], CXP - collision cell exit potential [V]

Fig. 2 Typical LC-MS/MS chromatograms of fungicides in raw tomato sample (1 and 2: MS/MS transition ions)

each experiment $t_{1 / 2}=\ln 2 / k$, while the theoretical dissipation time to reach the level of $0.01 \mathrm{mg} / \mathrm{kg}$ was calculated according to equation $t_{0.01}=\ln \left(0.01 / C_{0}\right) /(-k)$.

\section{Health risk estimation}

The health risk estimation through the comparison of detected fungicide residues with the established acceptable daily intake (ADI) or acute reference dose (ARfD) (JMPR 2006) was calculated. The long-term and short dietary consumer exposure to pesticide residues was estimated by using an EFSA calculation model developed by EFSA (EFSA calculation model Pesticide Residue Intake Model "PRIMo", revision 2) for two sub-populations, children (2-4 years) and adults (14-80 years). This model based on national food consumption and unit weights and implements internationally agreed risk assessment methodologies to assess the exposure of consumers, accepting consumption at the level of the
97.5 percentile based on the available epidemiological studies carried out for British (PSD 2006) and Italian population (GEMS/FOOD 2012), because data for Polish consumers are available only for general population.

\section{Long-term risk assessment}

In this study, long-term risk assessment was performed for initial deposits of fungicides obtained at single dose. The acceptable daily intake (ADI) is the estimated amount of a substance in food, expressed on a body weight basis, that can be ingested daily over a lifetime, without appreciable chronic, long-term risk to any consumer. The international estimated daily intake (IEDI) was calculated according to the following formula, where $\mathrm{Fi}$-food-consumption data and RLi-residue level in the commodity: $\mathrm{IEDI}=(\mathrm{Fi} \times \mathrm{RLi}) /$ mean_body_weight. The long-term risk assessment was performed by calculating the hazard 
quotient (HQ) by dividing the international estimated daily intake by the relevant acceptable daily intake: $\mathrm{HQ}_{\text {Chronic }}=$ IEDI/ADI.

\section{Short-term risk assessment}

Short-term risk was estimated by comparing single intake of the highest detected residue of fungicide (HR) full portion consumption data for the commodity unit (F) to a set volume ARfD. The international estimated short-term intake (IESTI) was calculated for processed samples according to the following formulas (Renwick 2002): IESTI $=(\mathrm{F} \times \mathrm{HR}) /$ mean_body_weight (without correction for PF) and $\mathrm{IESTI}^{*}=(\mathrm{F} \times \mathrm{HR} * \mathrm{PF}) /$ mean_body_weight (correcting for $\mathrm{PF}$ ). In short-term risk assessment, $\mathrm{HQ}$ was calculated by the equation: $\mathrm{HQ}_{\text {Acute }}=\mathrm{IESTI} / \mathrm{ARfD}$. The assessment of the acute exposure was based on a worst-case scenario, i.e., consumption data for consumers with extreme food consumption habits were combined with the highest residue concentration.

\section{Results and discussion}

\section{Decline of fungicide residues}

The values of azoxystrobin, boscalid, chlorothalonil, cyprodinil, fludioxonil, and pyraclostrobin residues for two varieties Marissa and Harzfeuer of tomatoes are shown in Table 1 ( $a$ and $b$ ), respectively. The average initial residues of six fungicide residues for variety Marissa and for variety Harzfeuer were in the range 0.158-1.076 and 0.217$1.143 \mathrm{mg} / \mathrm{kg}$, respectively. At the end of the experiment, the concentration of pesticides decreased to 0.090-0.541 and $0.121-0.568 \mathrm{mg} / \mathrm{kg}$, which indicated that up to $99 \%$ of the initial deposits dissipated over the 21 days of the experiment. The dissipation rate of residues was initially faster but slowed down over time (Fig. 3), showing a non-linear trend that fitted with the first-order kinetic model. Figure 3 shows the regression equations and correlation coefficient for fungicides in both tomato varieties.

The half-life values $\left(t_{1 / 2}\right)$, theoretical dissipation time $\left(t_{0.01}\right)$ to reach the concentration of $0.01 \mathrm{mg} / \mathrm{kg}$ and dissipation rate constants $(k)$ of the six fungicides are summarized in Table 1. The half-life values of the pesticides were 2.49-5.00 days for variety Marissa and 2.67-5.32 days for variety Harzfeuer. The shortest half-life time for cyprodinil and the longest for chlorothalonil were noted in both varieties. The theoretical dissipation time was 9.26-21.72 and 9.77-27.33 days for variety Marissa and Harzfeuer, respectively. Pyraclostrobin was the fungicide which the fastest reach the level of $0.01 \mathrm{mg} / \mathrm{kg}$ while chlorothalonil the slowest. Residues dissipated below quantification limits at the twenty-first days except chlorothalonil and azoxystrobin.
The results of the present study were consistent with findings found in the literature. The half-life values of other fungicides have been previously reported to be 2.2 days for metalaxyl in cucumbers (Ramezani and Shahriari 2015) and 2.7 days for iprovalicarb in cabbage heads (Maity and Mukherjee 2009). It has been shown (Fig. 3) that most fungicide residues dissipated faster in variety Marissa that in variety Harzfeuer. This can be explained by the differences in size. Tomato fruits of variety Harzfeuer are about two times smaller than variety Marissa.

The pre-harvest intervals (PHIs) for all the studied fungicides were establish by the Polish government at 3 days in greenhouse-grown tomatoes. Roughly $49.72-74.73 \%$ of the initial deposits of pesticides were lost after PHIs for variety Marissa, while the dissipation was 39.89-75.20\% for variety Harzfeuer. Additionally, the longest dissipation time at residue level $0.01 \mathrm{mg} / \mathrm{kg}$ was obtained for chlorothalonil 21.72 and 27.33 days for Marissa and Harzfeuer variety, respectively. Chlorothalonil is a fairy persistent fungicide with long residual activity. Based on these observations, longer safety waiting periods are suggested for chlorothalonil in tomatoes, especially in the case of food intended for children.

\section{Unprocessed tomato samples}

The unprocessed tomato samples obtained from greenhouse trial with initial deposits of fungicides were necessary to calculate the processing factors which describe the efficiency of food processing in terms of reducing the pesticide residue level. With obtained concentrations of raw tomato samples (Table 2), processing factors have been calculated to estimate the level of pesticide exposure at the point of consumption after processing.

\section{Effect of processing and processing factors}

The level and nature of pesticide residues in food have always been changed during home processing (Li et al. 2011). Several studies have examined the effect of commercial or home processing on pesticide residue removal in fruits and vegetables (Aguilera et al. 2012; Amvrazi 2011; Bonnechere et al. 2012; Keikotlhaile et al. 2010). The processing techniques used in our studies focused on processing of tomatoes, including washing, peeling, homogenization, simmering, and canning. The experiment focused on concentration changes of azoxystrobin, boscalid, chlorothalonil, cyprodinil, fludioxonil, and pyraclostrobin and determination of processing factors (PFs) on each step during tomato paste production.

A processing study was performed to investigate the effect of particular technological steps on the residues of selected fungicides in two varieties of tomato fruits. Many factors could affect the removal of pesticide residue such as chemical property of pesticide, processing procedure, etc. 
Table 1 Fate of fungicides studied in two varieties of tomatoes: (a) variety Marissa and (b) variety Harzfeuer

\begin{tabular}{|c|c|c|c|c|c|c|c|c|c|c|c|c|}
\hline \multirow{2}{*}{$\begin{array}{l}\text { Days after } \\
\text { treatment }\end{array}$} & \multicolumn{2}{|l|}{ Azoxystrobin } & \multicolumn{2}{|l|}{ Boscalid } & \multicolumn{2}{|l|}{ Chlorothalonil } & \multicolumn{2}{|l|}{ Cyprodinil } & \multicolumn{2}{|l|}{ Fludioxonil } & \multicolumn{2}{|l|}{ Pyraclostrobin } \\
\hline & $\begin{array}{l}\text { Mean } \mathrm{C} \pm \mathrm{SD} \\
n=3\end{array}$ & $\mathrm{D} \%$ & $\begin{array}{l}\text { Mean } \mathrm{C} \pm \mathrm{SD} \\
n=3\end{array}$ & $\mathrm{D} \%$ & $\begin{array}{l}\text { Mean } \mathrm{C} \pm \mathrm{SD} \\
n=3\end{array}$ & $\mathrm{D} \%$ & $\begin{array}{l}\text { Mean } \mathrm{C} \pm \mathrm{SD} \\
n=3\end{array}$ & $\mathrm{D} \%$ & $\begin{array}{l}\text { Mean } \mathrm{C} \pm \mathrm{SD} \\
n=3\end{array}$ & $\mathrm{D} \%$ & $\begin{array}{l}\text { Mean } \mathrm{C} \pm \mathrm{SD} \\
n=3\end{array}$ & $\mathrm{D} \%$ \\
\hline \multicolumn{13}{|c|}{ (a) Variety Marissa } \\
\hline $0(1 \mathrm{~h})$ & $0.741 \pm 0.076$ & - & $0.158 \pm 0.017$ & - & $0.203 \pm 0.022$ & - & $0.425 \pm 0.044$ & - & $0.835 \pm 0.085$ & - & $0.108 \pm 0.013$ & - \\
\hline 1 & $0.552 \pm 0.060$ & 25.51 & $0.128 \pm 0.014$ & 18.99 & $0.180 \pm 0.022$ & 11.33 & $0.313 \pm 0.032$ & 26.35 & $0.588 \pm 0.060$ & 29.58 & $0.095 \pm 0.011$ & 11.25 \\
\hline 2 & $0.415 \pm 0.048$ & 43.99 & $0.108 \pm 0.012$ & 31.65 & $0.120 \pm 0.013$ & 40.89 & $0.236 \pm 0.025$ & 44.47 & $0.407 \pm 0.042$ & 51.26 & $0.081 \pm 0.009$ & 24.54 \\
\hline 3 & $0.215 \pm 0.023$ & 70.99 & $0.081 \pm 0.009$ & 48.73 & $0.090 \pm 0.011$ & 55.67 & $0.111 \pm 0.013$ & 73.88 & $0.211 \pm 0.026$ & 74.73 & $0.054 \pm 0.006$ & 49.72 \\
\hline 5 & $0.112 \pm 0.016$ & 84.89 & $0.049 \pm 0.006$ & 68.99 & $0.073 \pm 0.008$ & 64.04 & $0.081 \pm 0.009$ & 80.94 & $0.027 \pm 0.003$ & 96.77 & $0.017 \pm 0.002$ & 84.48 \\
\hline 8 & $0.083 \pm 0.009$ & 88.80 & $0.028 \pm 0.004$ & 82.28 & $0.066 \pm 0.007$ & 67.49 & $0.032 \pm 0.004$ & 92.47 & $0.014 \pm 0.002$ & 98.32 & $0.007 \pm 0.001$ & 93.68 \\
\hline 11 & $0.043 \pm 0.005$ & 94.20 & $0.012 \pm 0.002$ & 92.41 & $0.050 \pm 0.006$ & 75.37 & $0.011 \pm 0.002$ & 97.41 & $0.010 \pm 0.002$ & 98.80 & $<\mathrm{LOQ}$ & $<99$ \\
\hline 14 & $0.028 \pm 0.004$ & 96.22 & $0.006 \pm 0.001$ & 96.20 & $0.031 \pm 0.004$ & 84.73 & $<\mathrm{LOQ}$ & $>99$ & $0.009 \pm$ & 98.92 & $<\mathrm{LOQ}$ & $>99$ \\
\hline 21 & $0.010 \pm 0.003$ & 98.65 & $<\mathrm{LOQ}$ & $>99$ & $0.008 \pm 0.001$ & 96.06 & $<\mathrm{LOQ}$ & $>99$ & $<\mathrm{LOQ}$ & $>99$ & $<\mathrm{LOQ}$ & $>99$ \\
\hline$k$ & 0.2035 & & 0.2408 & & 0.1386 & & 0.2781 & & 0.2599 & & 0.2566 & \\
\hline$t_{1 / 2}$ & 3.41 & & 2.88 & & 5.00 & & 2.49 & & 2.67 & & 2.70 & \\
\hline$t_{0.01}$ & 21.16 & & 11.46 & & 21.72 & & 13.48 & & 17.03 & & 9.26 & \\
\hline \multicolumn{13}{|c|}{ (b) Variety Harzfeuer } \\
\hline $0(1 \mathrm{~h})$ & $0.917 \pm 0.094$ & - & $0.217 \pm 0.025$ & - & $0.351 \pm 0.040$ & - & $0.488 \pm 0.051$ & - & $0.909 \pm 0.094$ & - & $0.114 \pm 0.015$ & - \\
\hline 1 & $0.750 \pm 0.080$ & 18.21 & $0.186 \pm 0.021$ & 14.29 & $0.332 \pm 0.035$ & 5.41 & $0.328 \pm 0.0034$ & 32.79 & $0.570 \pm 0.059$ & 37.29 & $0.095 \pm 0.010$ & 16.71 \\
\hline 2 & $0.504 \pm 0.052$ & 45.04 & $0.171 \pm 0.019$ & 21.20 & $0.315 \pm 0.033$ & 10.26 & $0.232 \pm 0.025$ & 52.46 & $0.404 \pm 0.042$ & 55.56 & $0.081 \pm 0.009$ & 29.22 \\
\hline 3 & $0.293 \pm 0.031$ & 68.05 & $0.084 \pm 0.090$ & 61.29 & $0.211 \pm 0.025$ & 39.89 & $0.121 \pm 0.014$ & 75.20 & $0.243 \pm 0.026$ & 73.27 & $0.057 \pm 0.006$ & 50.31 \\
\hline 5 & $0.179 \pm 0.020$ & 80.48 & $0.044 \pm 0.005$ & 79.72 & $0.204 \pm 0.022$ & 41.88 & $0.037 \pm 0.004$ & 69.42 & $0.072 \pm 0.008$ & 92.08 & $0.013 \pm 0.001$ & 88.80 \\
\hline 8 & $0.135 \pm 0.015$ & 85.28 & $0.022 \pm 0.003$ & 89.86 & $0.164 \pm 0.017$ & 53.28 & $0.028 \pm 0.003$ & 94.26 & $0.025 \pm 0.003$ & 97.25 & $0.006 \pm 0.001$ & 94.66 \\
\hline 11 & $0.072 \pm 0.008$ & 92.15 & $0.017 \pm 0.002$ & 92.17 & $0.071 \pm 0.008$ & 79.77 & $0.009 \pm 0.001$ & 98.16 & $0.012 \pm 0.001$ & 98.68 & $0.005 \pm 0.001$ & 95.19 \\
\hline 14 & $0.039 \pm 0.005$ & 95.75 & $0.005 \pm 0.001$ & 98.16 & $0.063 \pm 0.007$ & 82.05 & $0.005 \pm 0.001$ & 99.18 & $0.008 \pm 0.001$ & 99.12 & $<\mathrm{LOQ}$ & $<99$ \\
\hline 21 & $0.015 \pm 0.001$ & 98.36 & $<\mathrm{LOQ}$ & $>99$ & $0.024 \pm 0.003$ & 93.16 & $<\mathrm{LOQ}$ & $>99$ & $0.007 \pm 0.001$ & 99.23 & $<\mathrm{LOQ}$ & $>99$ \\
\hline$k$ & 0.195 & & 0.224 & & 0.1302 & & 0.2597 & & 0.2552 & & 0.2494 & \\
\hline$t_{1 / 2}$ & 3.55 & & 3.09 & & 5.32 & & 2.67 & & 2.72 & & 2.78 & \\
\hline$t_{0.01}$ & 23.17 & & 13.74 & & 27.33 & & 14.97 & & 17.67 & & 9.77 & \\
\hline
\end{tabular}

Mean $C$ concentration (mg/kg), $S D$ standard deviation, $n$ number of replicates, $D$ dissipation, $k$ rate constant (days-1), $t_{1 / 2}$ half-life time (days), $t_{0.01}$ theoretical time to reach the level of $0.01 \mathrm{mg} / \mathrm{kg}$

Analyzed fungicides (Supplementary data, Table S1) belong to various chemical groups, e.g., anilinopyrimidine, carboxamide, chloronitrile, phenylpyrrole, and strobilurin according to Database of University of Hertfordshire (PPDB Pesticide Database) and have different health effects for humans (Supplementary data, Table S2). The effectiveness of each treatment depended on physico-chemical properties of the studied fungicides such as octanol-water partition coefficient $(\log \mathrm{P})$, solubility in water $\left(\mathrm{S}_{\mathrm{w}}\right)$, boiling point and molecular mass (M), and the mode of action. The concentration changes of fungicide residue in tomatoes after processing were presented in Table 2.

Washing is the first step in most processing methods. The effectiveness of washing in removing of residues depends on many factors (Kaushik et al. 2009) including the location of residue, the age of residue, the water solubility, the lipophilic character of the pesticide, and the washing technique (Holland et al. 1994). The traditional method of washing vegetables to remove debris and dirt has been assumed to reduce pesticide residues (Satpathy et al. 2012). In the present work, raw tomato samples were washed under running tap water. The results indicated that fungicides were reduced by $29-68 \%$ and 10-48 \% after washing for Marissa and Harzfeuer variety, respectively (MS2, HS2). It was noted that removal of contact pesticides like chlorothalonil and fludioxonil were higher in contrast to systemic cyprodinil or pyraclostrobin.

As shown in Table 2, the maximum fungicide residues were obtained from unwashed tomato skins (MS3, HS3). The amount of residues decreased up to 90 and $92 \%$ after the peeling process (MS5, HS5). This result indicated that pesticides were primarily deposited on the tomato skin. Cutin and wax may have important functions in physically protecting tomato fruit from pesticide deposition (Kimbara et al. 2012). A similar finding was studied by 

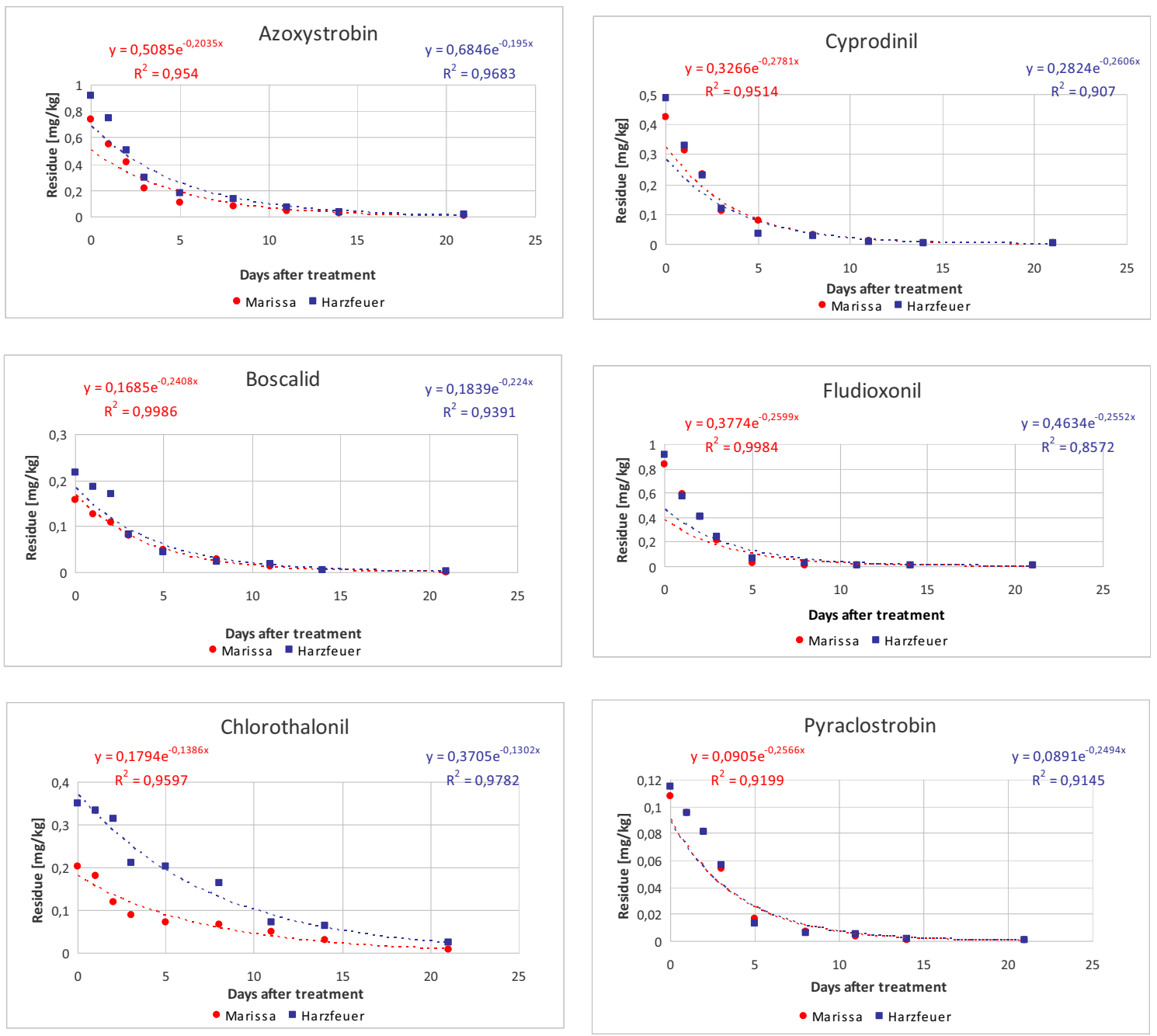

Fig. 3 Dissipation kinetics of active substances studied in two varieties of tomatoes

(Mourad Boulaid et al. 2005), who found that pyrifenox and tralomethrin residues cannot be detected in peeled tomato samples.

Peeling the tomatoes efficiently removed almost all fungicide residues, two non-systemic fungicides more efficiently compared to four systemic compounds. This was expected, as chlorothalonil and fludioxonil are non-systemic fungicides, making them immobile in plant tissue and therefore located on the outer surface of the peel. Whereas, azoxystrobin, boscalid, cyprodinil, and pyraclostrobin are systemic, making them mobile in plant tissue and penetrating deeper into the plant tissues. These fungicides might also end up in the tomato fruits via xylem and pholem transport from other parts of the plant, therefore being more present in the tomato pulp in addition to peel.

After peeling, tomatoes were cut into quarters, and the seeds and excess juice were removed. The juice was homogenized using a blender to preserve its taste. The data in Table 2 indicated that residues in tomato seeds and juice were below the LOQ in this study. These results may have been caused by the physico-chemical properties of pesticides, including their solubility in water. Fungicides studied are relatively insoluble in water (Supplementary data, Table S1), the solubility in water ranged from $0.81 \mathrm{mg} / \mathrm{l}$ for chlorothalonil to $13.00 \mathrm{mg} / \mathrm{l}$ for cyprodinil (at $20^{\circ} \mathrm{C}$ ). Thus, they are hardly transported into the internal parts of tomato juice (MS7, HS7) and tomato seeds (MS8, HS8) because of their low water solubility.

Many researchers have reported about reduction of pesticide concentration in different vegetables. Randhawa et al. (2007) found that peeling reduced $60-67 \%$ of the endosulfan residues in vegetables, whereas washing reduced $15-30 \%$ of these residues. Timme et al. and Burchat et al. reported results for the peeling and the juicing of carrots. According to them, peeling allows the elimination of residues and the juice was less concentrated in pesticide residues than the pulp (Timme and Walz-Tylla 2004; Burchat et al. 1998).

The next process was simmering and was applied to remove excess water from tomato puree. About $50 \%$ of the water in the tomatoes was evaporated. As shown in the Fig. 4, the residues in tomato paste (MS9, HS9) were reduced up to $92 \%$. The highest removal of initial deposits was 


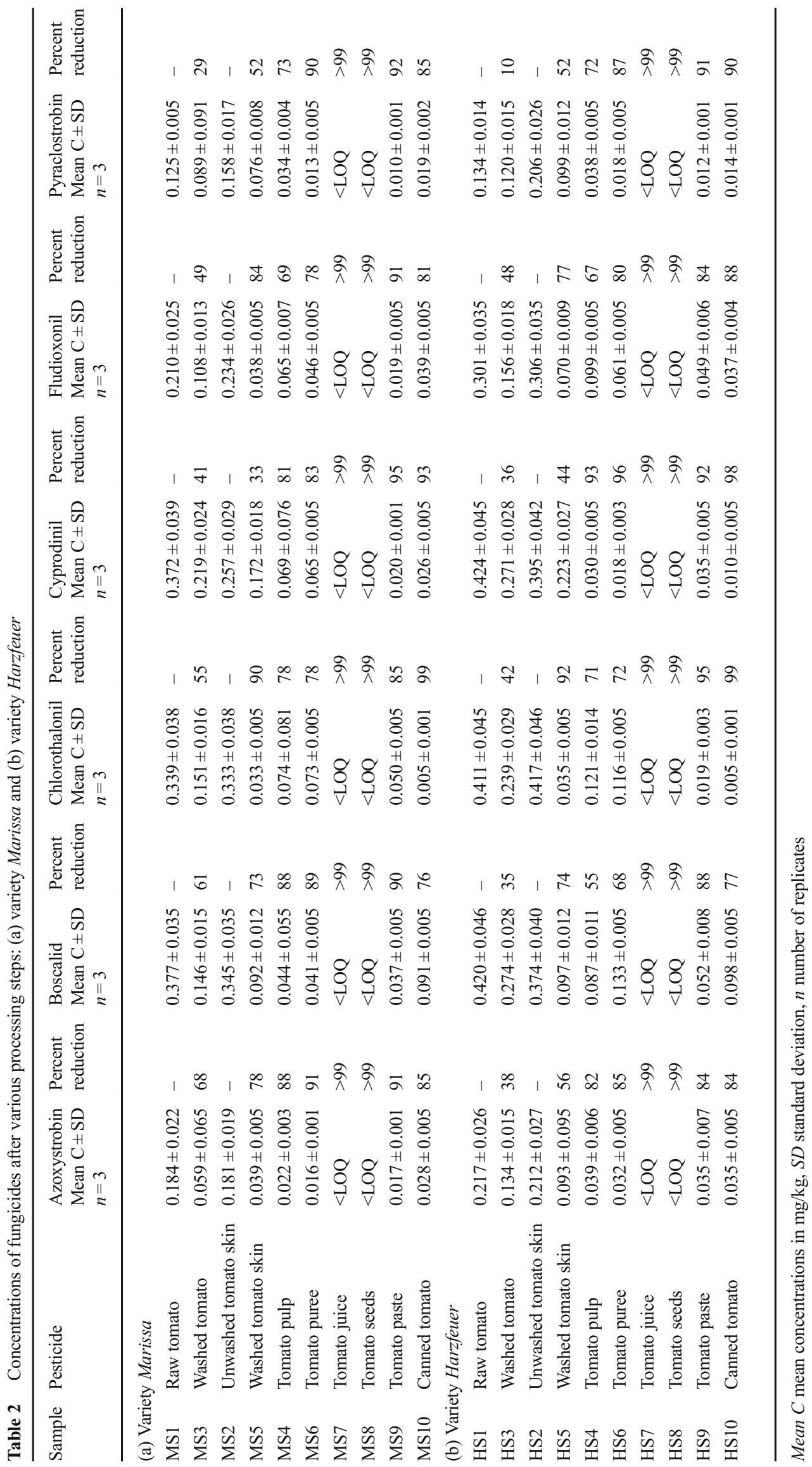




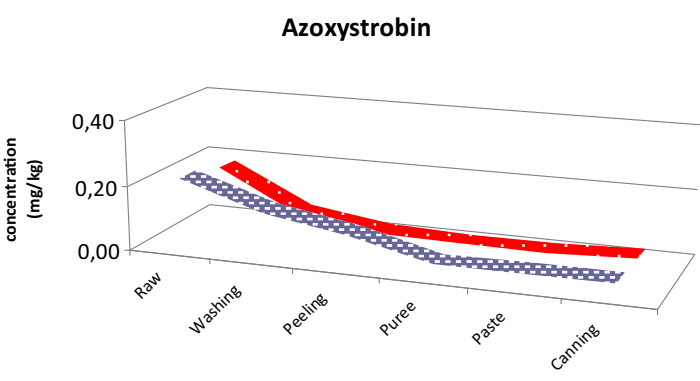

포 Harzfeuer Marissa

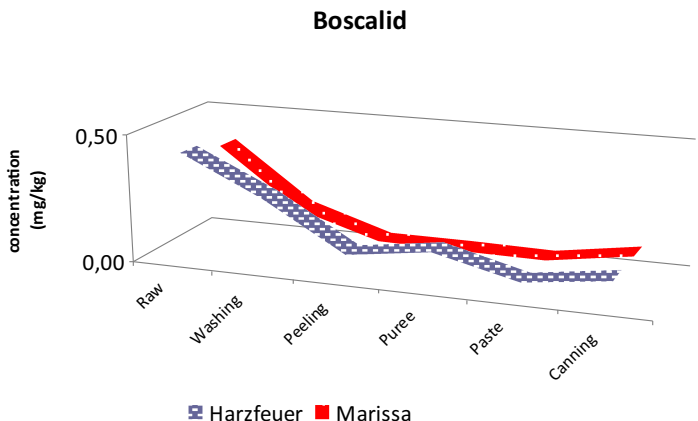

Chlorothalonil

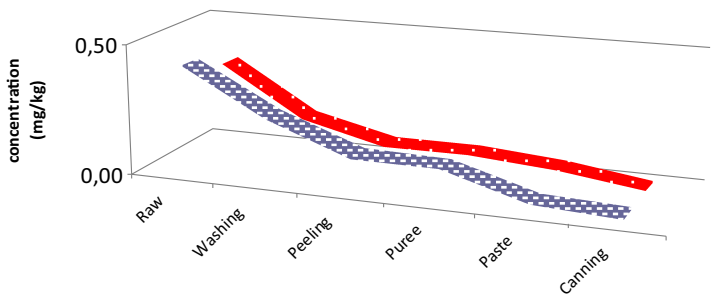

\$arzfeuer $n$ Marissa

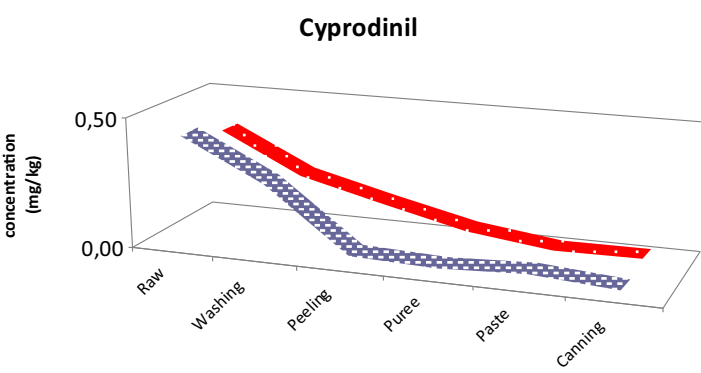

Harzfeuer Marissa

Fludioxonil

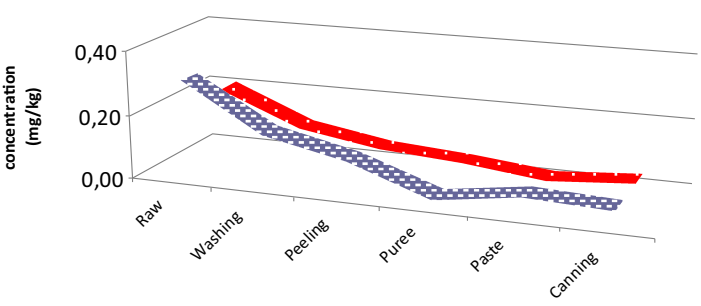

Harzfeuer Marissa

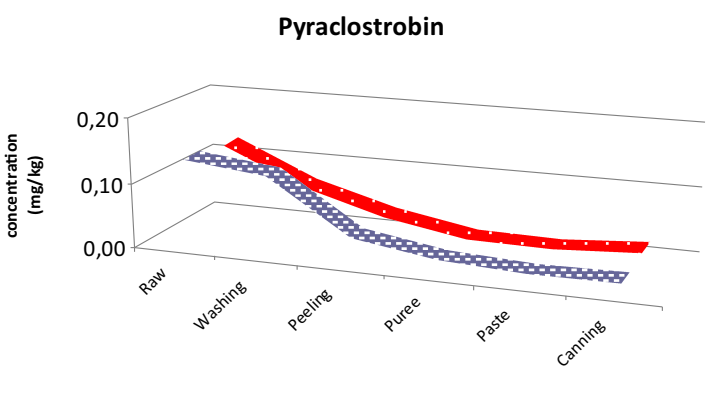

Harzfeuer Marissa

Fig. 4 Trends of fungicide content during processing in two varieties of tomatoes

observed for pyraclostrobin. Obtained high degradation of pyraclostrobin may be explained by the fact that during thermal processing, the loss of pesticide residues may be through evaporation, co-distillation, and thermal degradation and thus reduce residue levels (Holland et al. 1994).

The last step was canning of tomato paste carried at very high temperature (about $120{ }^{\circ} \mathrm{C}$ ). As shown in Table 2, the most pesticide residues in tomato paste were lower than those in canned tomatoes (MS10, HS10). This result may be explained by the fact that the pesticides were concentrated as the water evaporated from the tomatoes. However, in our study, one exception was noted. Chlorothalonil indicated almost complete reduction after canning in both varieties, with removal up to $99 \%$. It can be explained that during heat treatment, some of the pesticides are lost by volatilization or hydrolysis, and some of the compound can also be degraded. Similar findings were obtained by $\mathrm{Li}$ et al. (2011), who found that sterilization eliminated the cypermethrin and prochloraz residues.

The processing factor are calculated and considered by the Joint FAO/WHO Meeting on Pesticide Residues (JMPR) as follows (FAO/WHO 2012): $\mathrm{PF}=$ residues in processed tomatoes $(\mathrm{mg} / \mathrm{kg}) /$ residues in raw tomatoes $(\mathrm{mg} / \mathrm{kg})$. The PF values below 1 (i.e., reduction factor) indicate a reduction in residues in a processed commodity, whereas the values above 1 (i.e., concentration factor) indicate concentration effects from the processing procedures (Timme and Walz-Tylla 2004). Table 3 shows the calculated PFs for fungicides after processing in both varieties. The PFs were generally less than 1 , which indicates residue reduction in the processed tomato commodities. In particular, the general PF for studied fungicides obtained after washing was 0.57 , after peeling 0.24 , after simmering 0.10 , and after canning 0.12. The lowest PF value among the data obtained indicated washing 
Table 3 Processing factors (PFs) for individual processing steps for six pesticides in two varieties of tomatoes

\begin{tabular}{|c|c|c|c|c|c|c|}
\hline \multirow[t]{2}{*}{ Fungicide } & \multirow[t]{2}{*}{ Variety } & \multicolumn{5}{|l|}{$\mathrm{PF}^{\mathrm{a}}$} \\
\hline & & Washing & Peeling & Homogenization & Simmering & Canning \\
\hline \multirow[t]{2}{*}{ Azoxystrobin } & M & 0.32 & 0.12 & 0.09 & 0.09 & 0.15 \\
\hline & $\mathrm{H}$ & 0.62 & 0.18 & 0.15 & 0.16 & 0.16 \\
\hline \multirow[t]{2}{*}{ Boscalid } & M & 0.39 & 0.12 & 0.11 & 0.10 & 0.24 \\
\hline & $\mathrm{H}$ & 0.65 & 0.45 & 0.32 & 0.12 & 0.23 \\
\hline \multirow[t]{2}{*}{ Chlorothalonil } & M & 0.45 & 0.22 & 0.22 & 0.15 & 0.01 \\
\hline & $\mathrm{H}$ & 0.58 & 0.29 & 0.28 & 0.05 & 0.01 \\
\hline \multirow[t]{2}{*}{ Cyprodinil } & M & 0.59 & 0.19 & 0.17 & 0.05 & 0.07 \\
\hline & $\mathrm{H}$ & 0.64 & 0.07 & 0.04 & 0.08 & 0.02 \\
\hline \multirow[t]{2}{*}{ Fludioxonil } & M & 0.51 & 0.31 & 0.22 & 0.09 & 0.19 \\
\hline & $\mathrm{H}$ & 0.52 & 0.33 & 0.20 & 0.16 & 0.12 \\
\hline \multirow[t]{2}{*}{ Pyraclostrobin } & M & 0.71 & 0.27 & 0.10 & 0.08 & 0.15 \\
\hline & $\mathrm{H}$ & 0.90 & 0.28 & 0.13 & 0.09 & 0.10 \\
\hline General PF & & 0.57 & 0.24 & 0.17 & 0.10 & 0.12 \\
\hline
\end{tabular}

${ }^{\text {a }} \mathrm{PF}$ for individual processing steps were obtained from samples MS3, HS3 in washing; MS4, HS4 in peeling; MS6, HS6 in homogenization; MS9, HS9 in simmering; MS10, HS10 in canning followed by peeling and simmering and thus they played the most important role in effectively removing residues from both varieties of tomatoes.

Figure 4 shows the trend of fungicide content during processing in both varieties of tomatoes. The general trend of reduction of pesticide residues by certain methods of food processing for a particular active ingredient was noted. Figure 4 shows some differences between varieties, especially in concentrations after washing step. Although, primary deposits of fungicides were higher in variety Harzfeuer than in variety Marissa, the final concentrations in canned tomato paste were close in both varieties. It could be concluded that proportion peels/ pulp was more important and engendered variations between varieties which were leveled during processing.

\section{Safety evaluation}

The value of ADI for azoxystrobin, boscalid, chlorothalonil, cyprodinil, fludioxonil, and pyraclostrobin is $0.2,0.04,0.015$, $0.03,0.37$, and $0.03 \mathrm{mg} / \mathrm{kg}$, respectively, and ARfD is available only for chlorothalonil and pyraclostrobin 0.60 and $0.03 \mathrm{mg} / \mathrm{kg}$, respectively. Consumption of tomatoes at 97.5 percentile per person is $6.4643 \mathrm{~g} / \mathrm{kg}$ body weight (bw) for British children and $4.0428 \mathrm{~g} / \mathrm{kg}$ bw for British adults, whereas for Italian population is $9.1576 \mathrm{~g} / \mathrm{kg}$ bw for Italian toddlers and $3.0231 \mathrm{~g} / \mathrm{kg}$ bw for Italian adults.

\section{Chronic risk assessment}

In the present study, with the first-day concentration of fungicides at recommended dose, the estimated daily intakes were found to be IEDI $=0.69 * 10^{-3}-5.88 * 10^{-3}$ (fludioxonil) $\mathrm{g} / \mathrm{kg}$ body weight/day for children and IEDI $=0.38 * 10^{-3}-3.22 * 10^{-3} \mathrm{~g} / \mathrm{kg}$ body weight/day for adults. The calculated percent IEDI and ADI ratios ranged between $\mathrm{HQ}_{\text {Chronic }}=2.3-15.1 \%$ and $\mathrm{HQ}_{\text {Chronic }}=0.8$ $8.3 \%$ for British children and adults, respectively. In contrast for Italian population, toddlers eat about three times more than adults, thus IEDI ranged from $0.98 * 10^{-3}$ to $8.32 * 10^{-3} \mathrm{~g} / \mathrm{kg}$ body weight/day for toddlers and from $0.32 * 10^{-3}$ to $2.74 * 10^{-3} \mathrm{~g} / \mathrm{kg}$ body weight/day for adults with hazard quotient values $\mathrm{HQ}_{\text {Chronic }}=2.1-21.4 \%$ and $\mathrm{HQ}_{\text {Chronic }}=0.7-7.1 \%$, respectively. For both population, the lowest $\mathrm{HQ}_{\text {Chronic }}$ value was for fludioxonil while the highest for chlorothalonil. Chlorothalonil is a compound from chloronitriles and is also considered to be a carcinogen for humans (Supplementary data, Table S2), so it is important to respect pre-harvest intervals of this fungicide to prevent excessive residues on the harvested crop.

\section{Acute risk assessment}

The dietary exposure was also calculated for initial deposits at double dose. In case of unavailability of ARfD, we accepted the ADI value for calculations. For British population, IESTI ranged from $0.81 * 10^{-3}$ to $2.74 * 10^{-3} \mathrm{~g} / \mathrm{kg}$ body weight/day for children and IESTI from $0.44 * 10^{-3}$ to $1.50^{*} 10^{-3} \mathrm{~g} / \mathrm{kg}$ body weight/ day for adults with $\mathrm{HQ}_{\text {Acute }}=0.4-9.1 \%$ and $\mathrm{HQ}_{\text {Acute }}=0.2-5.0 \%$, respectively. While calculated IESTI for Italian children ranged from $0.11 * 10^{-3}$ to $3.88 * 10^{-3} \mathrm{~g} / \mathrm{kg}$ body weight/day and for Italian adults from $0.38 * 10^{-3}$ to $1.28 * 10^{-3} \mathrm{~g} / \mathrm{kg}$ body weight/day with 


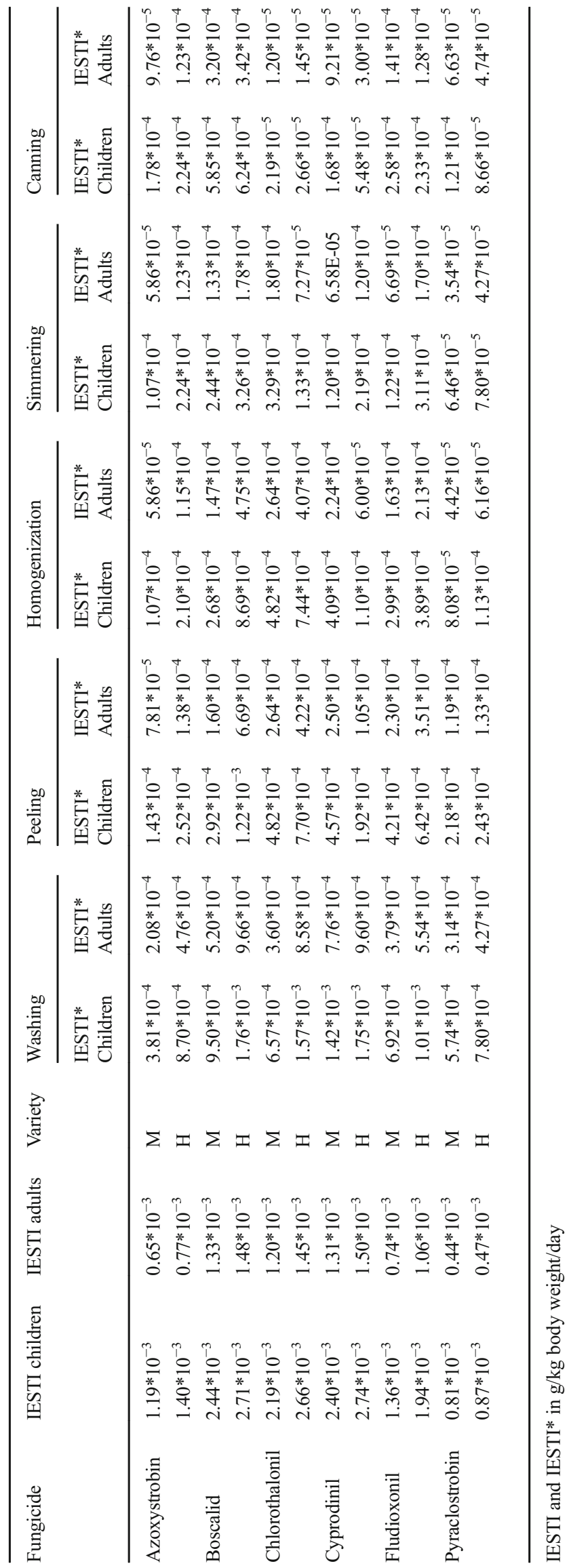


$\mathrm{HQ}_{\text {Acute }}=0.5-12.9 \%$ and $\mathrm{HQ}_{\text {Acute }}=0.2-4.3 \%$, respectively. Interestingly for both populations, the lowest $\mathrm{HQ}_{\text {Acute }}$ value was obtained for chlorothalonil while the highest for cyprodinil. This can be explained by the fact that chlorothalonil has its ARfD value forty times higher than ADI.

\section{Intake corrections}

The acute intakes (IESTI for British population) obtained for fungicide levels at pre-harvest intervals after double-dose application have been used to intake corrections. The acute risk assessment calculation has been performed for both varieties of tomatoes after each processing treatment. Intakes for British children and adults have been corrected with PFs and are shown in Table 4. After multiplying the assessed intakes with processing factors obtained for pesticides at each step during canned tomato paste production (washing, peeling, homogenization, simmering, and canning). IESTI* for children and adults are presented in Table 4. No significant effects of fungicide residues in tomatoes on human health were observed because the values were relatively low.

Including PFs in the intakes for children was below $1.76^{*} 10^{-3}, 1.22 * 10^{-3}, 8.69 * 10^{-4}, 3.29 * 10^{-4}$, and $6.24 * 10^{-4} \mathrm{~g} / \mathrm{kg}$ body weight/day after washing, peeling, homogenization, simmering, and canning, respectively, with $\mathrm{HQ}_{\text {Acute }}$ below $4.4 \%$. For adults, IESTI* was reduced to $9.66 * 10^{-4}, 6.69 * 10^{-4}, 4.75 * 10^{-4}, 1.80 * 10^{-4}$, and $3.42 * 10^{-4} \mathrm{~g} / \mathrm{kg}$ body weight/day after washing, peeling, homogenization, simmering, and canning, respectively, with $\mathrm{HQ}_{\text {Acute }}$ below $2.4 \%$. The HQ estimated from acute dietary exposure was above $20 \%$ and after intake correction was reduced to $4 \%$. This finding indicated that the processing steps obviously reduced pesticide residues and corresponding risks to consumer health.

\section{Conclusion}

In the current work, distribution of azoxystrobin, boscalid, chlorothalonil, cyprodinil, fludioxonil, and pyraclostrobin in two varieties Marissa and Harzfeuer cultivated in greenhouse were evaluated. The persistence of the fungicides was in the following order: cyprodinil $>$ fludioxonil $>$ pyraclostrobin $>$ boscalid $>$ azoxystrobin $>$ chlorothalonil. The effects of washing, peeling, homogenization, simmering, and sterilization on these fungicide residues in two varieties of tomato were also determined. The concentrations of pesticide residues significantly decreased in canned tomato paste by home processing. The processing factors obtained for a particular combination of fungicide/processing treatment allowed to better understand the removal effects of different pesticide residues in processed tomatoes by washing, peeling, homogenization, simmering, and canning. The reduction of the pesticides depended on the physico-chemical properties and systemic character of the pesticides and allowed to make assumptions to explain the difference in the processing factors for the studied pesticides. The evaluated dietary exposure after correction for PFs of all fungicides indicated no relevant risk to consumers as well children and adults. Therefore, tomato paste did not cause adverse effects on human health, especially for the most vulnerable population small children.

These results provided valuable information regarding the behavior of fungicides during tomato paste production as well as the effective role of technology in removing residues from tomato and reducing health risk of consumers. Reducing the frequency and levels of pesticides in food will build consumer confidence in the safety of fresh produce and is a solid step in the right direction in promoting healthier dietary consumption patterns.

Acknowledgments The authors are thankful to Mrs Ewa Rutkowska and Mrs Patrycja Mojsak for their help during the research.

\section{Compliance with ethical standards}

Funding This study was funded by the National Science Centre in Poland under Grant DEC-2012/07/N/NZ9/00043 (PRELUDIUM, "The risk assessment of consumers' exposure to pesticide residues in food after processing treatments").

Conflict of interest The authors declare that they have no conflict of interest.

Open Access This article is distributed under the terms of the Creative Commons Attribution 4.0 International License (http:// creativecommons.org/licenses/by/4.0/), which permits unrestricted use, distribution, and reproduction in any medium, provided you give appropriate credit to the original author(s) and the source, provide a link to the Creative Commons license, and indicate if changes were made.

\section{References}

Aguilera A, Valverde A, Camacho F, Boulaid M, Garcia-Fuentes L (2012) Effect of household processing and unit to unit variability of azoxystrobin, acrinathrin and kresoxim methyl residues in zucchini. Food Control 25:594-600. doi:10.1016/j.foodcont.2011.11.038

Amvrazi EG (2011) Fate of pesticide residues on raw agricultural crops after postharvest storage and food processing to edible portions. Pesticides-formulations, effects, fate. http://www.intechopen. $\mathrm{com} /$ books/pesticidesformulations-effects-fate/fate-of-pesticideresidues-on-raw-agricultural-crops-after-postharvest-storage-andfood-processing-t. Accessed 13 May 2015

Berrada H, Fernandez M, Ruiz MJ, Molto JC, Font G (2010) Surveillance of pesticide residues in fruits from Valencia during 
twenty months (2004/05). Food Control 21:36-44. doi:10. 1016/j.foodcont.2009.03.011

Bonnechere A, Hanot V, Bragard C, Bedoret T, van Loco J (2012) Effect of household and industrial processing on the levels of pesticide residues and degradation products in melons. Food Addit Contam A Chem Anal Control Expo Risk Assess 29:1058-1066. doi:10. 1080/19440049.2012.672339

Boulaid M, Aguilera A, Camacho F, Soussi M, Valverde A (2005) Effect of household processing and unit-to-unit variability of pyrifenox, pyridaben, and tralomethrin residues in tomatoes. J Agr Food Chem 53:4054-4058. doi:10.1021/jf040455y

Burchat CS, Ripley BD, Leishman PD, Ritcey GM, Kakuda Y, Stephenson GR (1998) The distribution of nine pesticides between the juice and pulp of carrots and tomatoes after home processing. Food Addit Contam 15:61-71. doi:10.1080/02652039809374599

Certel M, Cengiz MF, Akcay M (2011) Kinetic and thermodynamic investigation of mancozeb degradation in tomato homogenate during thermal processing. J Sci Food Agric 92:534-541. doi:10.1002/jsfa.4603

Document No. SANCO/12571/2013 (2014) Guidance document on analytical quality control and validation procedures for pesticide residues analysis in food and feed. http://ec.europa.eu/food/plant/ protection/resources/qualcontrol_en.pdf. Accessed 12 May 2015

EFSA calculation model Pesticide Residue Intake Model "PRIMo" revision 2. http://www.efsa.europa.eu/en/applications/pesticides/tools. Accessed 13 January 2016

EFSA Journal (2015) European Union report on pesticide residues in food. EFSA 13:4038. doi:10.2903/j.efsa.2015.4038

European Standard (2008) EN 15662:2008. Foods of plant origin Determination of pesticide residues using GC-MS and/or LC-MS/ MS following acetonitrile extraction/partitioning and clean-up by dispersive SPE - Quechers-method

FAO/WHO (2012) Updating the principles and methods of risk assessment: MRLs for pesticides and veterinary drugs. FAO, Rome

GEMS/FOOD (2012) Global Environment Monitoring System/Food Consumption Cluster Diets. World Health Organization, Geneva, https://extranet.who.int/sree/Reports?op=vs\&path=/WHO_HQ Reports/G7/PROD/EXT/GEMS_cluster_diets_2012\&userid=G7 ro\&password=inetsoft123. Accessed 12 May 2016

Han D, Tang B, Tian M, Row KH (2013) Solid-phase extraction combined with dispersive liquid-liquid microextraction for the determination of three benzimidazole pesticides (carbendazim, thiabendazole, and thiophanate-methyl) in tomatoes. Anal Lett 46: 557-568. doi:10.1080/00032719.2012.726682

Hixson JE (2015) Growing Tomatoes Like A Pro: How to Grow Juicy, Colorful, Tasty, Organic Tomatoes in Your Backyard \& in Containers. Living Plus Healthy Publishing, 106

Holland PT, Hamilton D, Ohlin B, Skidmore MW (1994) Effects of storage and processing on pesticide residues in plant products. Pure Appl Chem 66:335-356. doi:10.1351/pac199466020335

https://books.google.pl/books?id=QIdjCAAAQBAJ\&printsec= frontcover\&hl $=\mathrm{pl} \& \operatorname{source}=\mathrm{gbs}$ ge_summary_r\&cad$=0 \# \mathrm{v}=$ onepage $\& q \& \mathrm{f}=$ false. Accessed 12 January 2016

JMPR (2006) Pesticide toxicological reference values. http://www.efsa. europa.eu/en/mrls/docs/toxicovaluesr.pdf. Accessed 20 January 2015

Kaushik G, Satya S, Naik SN (2009) Food processing a tool to pesticide residue dissipation — a review. Food Res Int 42:26-40. doi:10.1016/ j.foodres.2008.09.009

Keikotlhaile BM, Spanoghe P, Steurbaut W (2010) Effects of food processing on pesticide residues in fruits and vegetables: a metaanalysis approach. Food Chem Toxicol 48:1-6. doi:10.1016/j.fct. 2009.10.031

Kimbara J, Yoshida M, Ito H, Hosoi K, Kusano M, Kobayashi M, Ariizumi T, Asamizu E, Ezuraal H (2012) A novel class of sticky peel and light green mutations causes cuticle deficiency in leaves and fruits of tomato (Solanum lycopersicum). Planta 236:1559 1570. doi:10.1007/s00425-012-1719-6
Lee MG, Jung D (2009) Processing factors and removal ratios of select pesticides in hot pepper leaves by a successive process of washing, blanching, and drying. Food Sci and Biotechnol 18:1078-1082

Lentza-Rizos C, Balokas A (2001) Residue levels of chlorpropham in individual tubers and composite samples of postharvest-treated potatoes. J Agr Food Chem 49:710-714. doi:10.1021/jf000018t

Li Y, Jiao B, Zhao Q, Wang C, Gong Y, Zhang Y, Chen W (2011) Effect of commercial processing on pesticide residues in orange products. Eur Food Res Technol 234:449-456. doi:10.1007/s00217-011-1651-1

Ling Y, Wang H, Yong W, Zhang F, Sun L, Yang ML, Wu YN, Chu XG (2011) The effects of washing and cooking on chlorpyrifos and its toxic metabolites in vegetables. Food Control 22:54-58. doi:10. 1016/j.foodcont.2010.06.009

Łozowicka B (2015) Health risk for children and adults consuming apples with pesticide residue. Sci Total Environ 502:184-198. doi:10.1016/ j.scitotenv.2014.09.026

Łozowicka B, Jankowska M, Kaczyński P (2009) Pesticide residues in Brassica vegetables and exposure assessment of consumers. Food Control 25:561-575. doi:10.1016/j.foodcont.2011.11.017

Łozowicka B, Abzeitova E, Sagitov A, Kaczynski P, Toleubayev K, Li A (2015) Studies of pesticide residues in tomatoes and cucumbers from Kazakhstan and the associated health risks. Environ Monit Assess 187:609. doi:10.1007/s10661-015-4818-6

Maity A, Mukherjee I (2009) Assessment of iprovalicarb, a systemic fungicide in/on cabbage (Brassica oleracea var. capitata). Bull Environ Contam Toxicol 83:341-347. doi:10.1007/s00128-009-9645-4

Matyjaszczyk E (2015) Prevention methods for pest control and their use in Poland. Pest Manag Sci 71:485-491. doi:10.1002/ps.3795

Mourad Boulaid A, Camacho F, Soussi M, Valverde A (2005) Effect of household processing and unit-to-unit variability of pyrifenox, pyridaben, and tralomethrin residues in tomatoes. J Sci Food Agr 53:4054-4058. doi:10.1021/jf040455y

EU Pesticide MRLs Database http://ec.europa.eu/sanco_pesticides/ public/?event=homepage. Accessed 12 November 2014

Pico Y, la Farre M, Soler C, Barcelo D (2007) Identification of unknown pesticides in fruits using ultra-performance liquid chromatographyquadrupole time-of-flight mass spectrometry. Imazalil as a case study of quantification. J Chrom A 1176:123-134

Polish Ministry of Agriculture web site. The register of plant protection products. http://www.bip.minrol.gov.p1/DesktopDefault.aspx? TabOrgId $=647 \&$ LangId $=0$. Accessed 01 December 2014

PPDB Pesticide Properties Database http://sitem.herts.ac.uk/aeru/ footprint/en/. Accessed 12 November 2014

Ramezani MK, Shahriari D (2015) Dissipation behaviour, processing factors and risk assessment for metalaxyl in greenhouse-grown cucumber. Pest Manag Sci 71:579-583. doi:10.1002/ps.3859

Randhawa MA, Anjum FM, Asi MR, Butt MS, Ahmed A, Randhawa MS (2007) Removal of endosulfan residues from vegetables by household processing. J Sci Ind Res 66:849-852

Rasmusssen RR, Poulsen ME, Hansen HC (2003) Distribution of multiple pesticide residues in apple segments after home processing. Food Addit Contam 20:1044-1063. doi:10.1080/ 02652030310001615221

Renwick AG (2002) Pesticide residue analysis and its relationship to hazard characterization (ADI/ARfD) and intake estimations (NEDI/NESTI). Pest Manag Sci 58:1073-1082. doi:10.1002/ps.544

PSD (Pesticides Safety Directorate) (2006). New intake calculation models for consumer intake assessments. http://www.detergents. gov.uk/approvals.asp?id=1687. Accessed 13 January 2016

Sakaliene O, Koskinen WC, Blazauskiene G, Petroviene I (2009) Level and fate of chlorpropham in potatoes during storage and processing. J Environ Sci Health B 44:1-6. doi:10.1080/03601230802519470

Salghi R, Luis G, Rubio C, Hormatallah A, Bazzi L, Gutiérrez AJ, Hardisson A (2012) Pesticide residues in tomatoes from greenhouses in Souss Massa Valley, Morocco. Bull Environ Contam Toxicol 88:358-361. doi:10.1007/s00128-011-0503-9 
Satpathy G, Tyagi YK, Gupta RK (2012) Removal of organophosphorus (OP) pesticide residues from vegetables using washing solutions and boiling. J Agr Sci 4:69-78. doi:10.5539/jas.v4n2p69

Timme G, Walz-Tylla B (2004) Effects of food preparation and processing on pesticide residues in commodities of plant origin, Pesticide Residues in Food and Drinking Water 121-148
Ucles S, Belmonte N, Mezcua M, Martínez AB, Martinez-Bueno MJ, Gamón M, Fernández-Alba AR (2014) Validation of a multiclass multiresidue method and monitoring results for 210 pesticides in fruits and vegetables by gas chromatography-triple quadrupole mass spectrometry. J Environ Sci Health B 49:557-568. doi:10.1080/ 03601234.2014 .911566 